\title{
BIPOLARIDAD TURÍSTICA EN EUROPA. LA CONSOLIDACIÓN DE DESTINOS MADUROS EN ÉPOCA DE CRISIS
}

\author{
Mercedes Jiménez García \\ Antonio Rafael Peña Sánchez. \\ José Ruiz Chico \\ Universidad de Cádiz
}

\section{RESUMEN}

En esta investigación, de carácter exploratorio, se aborda la posible relación entre algunas de las causas de la crisis turística y la respuesta de los diferentes territorios de la UE-28 a la actual crisis. En este sentido, se analiza si ésta ha afectado de manera diferente a las economías turísticamente emergentes frente a destinos europeos turísticamente más consolidados. La confirmación de este hecho lleva a estudiar qué factores determinantes de la demanda turística tienen mayor presencia en cada destino, concluyendo que los factores más relevantes, como los de carácter económico e infraestructural, se encuentran, sobre todo, en las regiones turísticamente más maduras. Esto puede explicar, en parte, que durante la crisis, estas regiones hayan experimentado un descenso de su crecimiento turístico no tan pronunciado como el de las regiones emergentes. Se demuestra así un comportamiento turístico mucho más estable y su consolidación en el sector.

Palabras clave: NUTS-2; turismo; destinos tradicionales; destinos emergentes; cluster.

Recibido: 22 de abril de 2015

Devuelto para su revisión: 9 de octubre de 2015

Aceptado: 20 de noviembre de 2015

Departamento de Economía General, Universidad de Cádiz Facultad de Ciencias Sociales y de la Comunicación. Campus Universitario de Jerez de la Frontera. Avda. de la Universidad, s/n. 11405 Jerez de la Frontera. CÁDIZ (España).E-mail: mercedes.jimenezgarcia@uca.es, rafael.pena@uca.es,jose.ruizchico@uca.es 


\title{
Tourist bipolarity in Europe. The consolidation of mature destinations in times of crisis
}

\begin{abstract}
In this exploratory research, it is presented the possible relationship between some of the causes of the tourism crisis and the response of different parts of the EU -28 to the current crisis. In this sense, we analyze if the crisis has affected differently to touristic emerging economies compared to the European touristic destinations, which are more consolidated. The confirmation of this fact leads to study what determinant factors of tourism demand have a greater presence in each destination, concluding that the most relevant factors, such as economics and infrastructural nature, are especially in the more mature regions for tourism. This can explain partly that these regions have experienced a decline in tourism growth not as pronounced as in emerging regions during the crisis. It is proved a much more stable tourist behavior and its consolidation in the sector.
\end{abstract}

Keywords: NUTS-2; tourism; traditional destinations; emerging destinations; cluster.

\section{INTRODUCCIÓN}

En los últimos años, la industria del turismo se ha convertido en un sector que se configura como motor de la economía de muchos países, tanto desarrollados como emergentes (Nel-lo y Pérez, 2007; Moreno y Picazo, 2012). No obstante, la situación de crisis económico-financiera por la que están atravesando las diferentes economías a nivel mundial ha motivado un comportamiento diferente en los distintos sectores, entre ellos el turístico.

Tanto turismo como crisis son dos temáticas ampliamente tratadas en la literatura, por su importancia y grado de actualidad. De esta manera, se pueden encontrar numerosos estudios relativos a los efectos de la actual crisis en el sector turístico, en diferentes estratos geográficos (desde niveles municipales hasta regionales, nacionales y supranacionales) y desde diferentes ópticas (desde el punto de vista empresarial, de los trabajadores turísticos, de la oferta hotelera, etc.) (véanse, a título de ejemplo, Morales, 2009; Pulido, 2009; Rodríguez y Alonso, 2009; Valenzuela, 2009; Mora y Morales, 2010; Perelli, 2010; Dorta, 2011; Monti, 2011; Morales, 2011; Prats, 2011; Aurioles, 2012; Sánchez et al., 2012; Güemez et al., 2013; entre otros).

No obstante, aunque los efectos de la crisis sobre el turismo se analizan con profusión, el ex - ante es menos tratado, encontrando, por una parte, trabajos que no tratan las causas de la crisis del turismo sino que mencionan al turismo (su estructura, su estacionalidad, su importancia relativa para la economía, etc.) como causante y/o catalizadores y propiciadores de la profundidad de la crisis en algunos territorios (Coscubiela, 2010; García, 2014); y por otra, análisis de las causas pero aplicadas a territorios muy concretos, es decir, estudios de casos (Garzón, 2011; González y Mantecón, 2014).

Es por todo ello que, los autores consideran de interés llevar a cabo un análisis, de carácter exploratorio dada la escasez de estudios previos, sobre un ámbito territorial 
extenso, la UE-28, en el que se aborden las causas de la crisis turística desde una visión diferente, en función de la respuesta de los diferentes destinos a la crisis. En este sentido, la crisis ha afectado al turismo a nivel general, no obstante, se considera interesante analizar si ésta ha afectado de manera diferente a las economías incipientes o en fase de crecimiento en turismo, tales como muchos de los países de Europa Oriental, frente a otra posible respuesta de destinos turísticamente más maduros y consolidados, como por ejemplo, los del Mediterráneo europeo. Así mismo, en el supuesto de la existencia de una respuesta diferenciada entre destinos, ¿a qué puede deberse?, una posible respuesta podría encontrarse, entre otros aspectos, en la presencia en los territorios de algunos de los principales factores causantes o atrayentes de la demanda turística analizados por la literatura. La importancia de determinar estas posibles diferencias entre destinos que, en su caso, pueden haber incidido y condicionado, en buena parte, su respuesta turística ante la actual situación de crisis, aumentaría el conocimiento sobre los aspectos que les otorgan una mayor influencia sobre su demanda turística actual y potencial y, por lo tanto, sobre su competitividad en el mercado (Molero y Valadez, 2005; Barroso y Flores, 2006; Garau, 2007; Lillo et al., 2007).

De esta manera, los objetivos planteados en este trabajo son, en primer lugar, analizar la posible existencia de una respuesta diferente del turismo en las regiones maduras y emergentes de la UE-28 durante la actual situación de crisis mundial. En segundo lugar, determinar si algunos de los factores mencionados por la literatura como incidentes en la demanda turística tienen mayor relevancia en la determinación de la misma que otros. En tercer lugar, conocer si los factores mencionados anteriormente se distribuyen por igual entre las regiones europeas y, en su caso, si existe alguna relación entre la presencia (o ausencia) de algunos de estos factores y el comportamiento de las llegadas turísticas a las diferentes regiones durante la crisis.

Para alcanzar los objetivos planteados, este trabajo se estructura de la siguiente manera; en el segundo apartado se presenta el marco teórico que comprende una breve referencia a la evolución de los países europeos en el sector turístico antes y durante la crisis, así como la revisión de los factores determinantes de la demanda turística según el análisis de diferentes autores. En el tercer apartado, se describen las diferentes fuentes de información utilizadas así como el marco metodológico aplicado para, en el cuarto epígrafe, proceder al análisis e interpretación de los principales resultados obtenidos. En el epígrafe final se reúnen las ideas y conclusiones más relevantes.

\section{MARCO TEÓRICO: EVOLUCIÓN Y FACTORES DETERMINANTES DEL TURISMO}

En la actualidad, siguiendo la clasificación de la Organización Mundial de Turismo (OMT), Europa es la primera región turística a nivel mundial, tanto por llegadas como por ingresos de turismo internacional (con una cuota de mercado del 51,8\% y del 42,2\%, respectivamente, para 2013) (OMT, 2014).

Entre sus principales destinos turísticos, atendiendo a las mismas variables, se encuentran países como Francia, España, Italia, Alemania o Reino Unido (OMT, 2014), muchos de ellos países tradicionalmente turísticos y especializados en dicho sector, como es el 
caso de España o Italia (que presentan un índice de especialización superior a 1). Otros destinos europeos especializados tradicionalmente en el sector del turismo son Grecia, Austria y Portugal, así como Reino Unido, aunque en este último caso, a partir del estallido de la actual crisis mundial (2007), comenzó a presentar índices anuales de especialización inferiores a la unidad ${ }^{1}$.

Europa ha venido experimentando en las últimas décadas una desaceleración de su crecimiento turístico, frente a un elevado crecimiento de otros destinos emergentes tales como Oriente Medio o Asia y el Pacífico (Jiménez, 2011:65). No obstante, esta desaceleración de las llegadas de turistas internacionales, no se ha producido en todos sus territorios por igual. De esta manera, se observa un ratio de crecimiento de llegadas turísticas del 6,4\% para el Centro y Este europeo, frente a un 2,1\% para la zona Oeste, en los años previos a la crisis (desde 1990 hasta 2007), mientras que los países del Norte y Sur y Mediterráneo europeos se encontraban en torno a la media europea (situada en un $3,6 \%$ ), con valores del $4,3 \%$ y $3,8 \%$, respectivamente. Se puede hablar, por tanto, de un importante crecimiento en la llegada de turistas en los países del Este, que se vio impulsado, sobre todo, por su adhesión a la Unión Europea y el cambio que esto conlleva a nivel económico, político, social, etc. (a partir de la quinta ampliación, en 2004 y las siguientes), frente a un crecimiento mucho menor de países tradicionalmente turísticos y ya maduros en este sector ${ }^{2}$.

La elevada elasticidad demanda-renta (superior a uno) del sector turístico (Witt y Witt, 1992; Esteban, 2004; Rosselló et al., 2005) fomenta una rápida recuperación del mismo en épocas de crisis (Morillo, 2009; Rodríguez-Toubes y Fraiz, 2011; Flores y Barroso,

1 El Índice de Especialización (IE) muestra la participación que un sector tiene en un país determinado, con relación a la participación de esa actividad en una escala territorial superior con la que se compara. Este índice puede tomar valores mayores, iguales o menores a la unidad, en función de que el territorio de estudio esté o no especializado en el sector analizado, respectivamente. Generalmente, el coeficiente de especialización es calculado a partir de los datos de la variable empleo o del valor agregado (PIB o VAB), y su expresión es la siguiente:

$$
I E_{i j}=\left[\frac{Y_{i j}}{\sum_{i} Y_{i j}} / \frac{\sum_{j} Y_{i j}}{\sum_{i} \sum_{j} Y_{i j}}\right]
$$

Donde, Y se refiere a la variable objeto de estudio, en este caso se ha empleado las cifras de VAB obtenidas de Eurostat para el periodo 1999-2013. Los subíndices i y j hacen referencia al sector y al territorio considerados, respectivamente (Rodríguez, 2005:29; Cuadrado y Maroto, 2012:9).

2 El concepto de destino turístico maduro se deriva de la «Teoría del Ciclo de Vida del destino turístico» de Butler (1980), modelo de referencia al hablar de la evolución de los destinos turísticos y uno de los que más interés y controversia ha generado, viéndose enriquecido, desde su aparición, con numerosos trabajos que detectaban algunas de sus limitaciones y/o proponían modificaciones de mejora(Douglas, 1997; Knowles y Curtis, 1999; Hovinen, 2002; Aguiló et al., 2005; Butler 2006a, 2006b; Oreja et al., 2008; Virgen, 2009; entre otros). Según dicha teoría, el crecimiento del área turística pasa, generalmente, por las fases de exploración, implicación, desarrollo, consolidación, estancamiento y post-estancamiento. Butler (1980) representa gráficamente su ciclo de vida relacionando la variable temporal con el número de turistas, por lo que los destinos maduros, tradicionalmente turísticos, pueden encontrarse situados en una fase de estancamiento, afectados por una pérdida de atractivo debido a las nuevas motivaciones de la demanda, o a la aparición de destinos emergentes competidores (Vera et al., 2011; Soares et al., 2012: 22 y ss.). En la actualidad, el modelo de Butler (1980) sigue considerándose válido en el análisis de los destinos turísticos, siendo uno de los más utilizados por numerosos autores (Lundtorp y Vanhill, 2001; Agarwal, 2002; Moore y Whitehall, 2005; Zielinski y Botero, 2011). 
2012:146), afirmación que se constata en la actual crisis económica, con una recuperación turística mucho antes que en el resto de sectores. No obstante, a pesar de ello, con la llegada de la crisis, el crecimiento del turismo europeo descendió hasta un 2,9\% (entre 2008 y 2013), motivado, fundamentalmente, por una caída en las tasas de los países de Europa del Centro y del Sur, situadas en el 3,5\% y $2,5 \%$ en ese periodo; mientras que los Estados miembros del Norte y occidente europeos mantuvieron tasas semejantes al periodo de bonanza económica precedente, con valores de $4,1 \%$ y $2,6 \%$, respectivamente (OMT, 2010 y 2014).

En definitiva, se puede decir que el fuerte crecimiento turístico de los países emergentes del Centro-Este europeo experimentado en los años anteriores a la crisis, no se está manteniendo durante la misma, sino que, por el contrario, estos países son los que están experimentando actualmente un mayor descenso en el ritmo de crecimiento turístico. Frente a esto, se observa el comportamiento de países turísticamente más maduros con un crecimiento inferior de sus llegadas en época de bonanza pero que, durante la crisis muestran un menor descenso en sus tasas de crecimiento. A título de ejemplo, por países, Lituania, Letonia y Bulgaria fueron los que presentaron las mayores tasas de crecimiento medio anual acumulado en el sector desde comienzos de siglo hasta la crisis (todos ellos superando el 10\%), frente a países como Grecia o Francia, cuyo crecimiento de las llegadas turísticas se situaban por debajo del $2 \%$. No obstante, a partir del comienzo de la crisis y hasta la actualidad, la mayor ralentización en el ritmo de crecimiento turístico se produce, precisamente en Lituania, Letonia y Bulgaria mientras que, por el contrario, Francia y Grecia presentan tasas de crecimiento mayores, incluso, que en los años previos a la misma3.

Por lo tanto, se observa que ante las transformaciones acontecidas en la economía mundial en los últimos años (actual crisis económico-financiera), la demanda turística que, hasta el momento se encontraba dispersa ante una oferta cada vez mayor (destinos emergentes competidores), ha tendido, durante la misma, a la concentración en los destinos maduros, más desarrollados, y con mejores condiciones económicas, sociales, de calidad de vida, etc. ${ }^{4}$

Tal y como menciona Perichi (2000:112), el turismo interno se obvia frecuentemente en los análisis sobre crecimiento del turismo mundial, en gran medida por la dificultad de su estimación. Según este mismo autor, este turismo puede llegar a representar para un país hasta diez veces el número de turistas extranjeros que lo visitan. En el caso de estudio que nos ocupa, se debe mencionar que, analizando las cifras proporcionadas por Eurostat, 5 el turismo interno en países como Francia, Bélgica o Alemania, ha experimentado tasas de crecimiento mayores durante la crisis que en los años previos a la misma, presentando un comportamiento similar al del turismo externo que visita estos países. Sin embargo,

3 Elaboración propia a partir de Eurostat (http://ec.europa.eu/eurostat/web/tourism/data/database), consultado el 19 de marzo de 2015.

4 Esta idea la avanzaba Torres (1994:100) en relación a otras crisis anteriores a la actual que también afectaron al sector turístico, y cuyas consecuencias son extrapolables a la situación presente. Existen otros numerosos trabajos en los que se relacionan el turismo con el grado de desarrollo del destino, véanse a título de ejemplo Vera y Marchena (1990), Muñoz (1992), Troitiño (1998), Andrés (2000), Punzo (2002), Delgado et al. (2003), Armesto y Gómez (2004) y Álvarez (2005), entre otros.

5 Ibid.

Cuadernos de Turismo, 38, (2016), 221-243 
en países del Este europeo, como Hungría o la República Checa, la tasa de crecimiento del turismo interno ha sido mayor durante la crisis que en los años previos a la misma, lo que ha permitido compensar, en parte, la ralentización en el crecimiento de las llegadas turísticas internacionales a partir del periodo de crisis.

Realizando una breve revisión bibliográfica sobre los motivos que pueden explicar el diferente comportamiento en la demanda turística, la mayoría de los autores coinciden con un conjunto de factores y variables que inciden directa o indirectamente en el volumen de llegadas, aunque se agrupan en diferentes categorías y denominación en función de la literatura consultada.

De esta manera, para Tocquer y Zins (1987), se distinguen entre factores externos (socioeconómicos, políticos, jurídicos y culturales), personales, sociológicos y psicológicos. Bull (1994) menciona variables económicas del origen, del destino, variables de conexión y otras (como el efecto moda). Pedreño y Monfort (1996) clasifican a los factores en función de su influencia en cada uno de los niveles de elección de la demanda turística. Para Vera (1997) se identifican las categorías de factores espaciales, ambientales y dinámicos. La OMT (1998) cita las categorías económica, psicológica, sociológica, física y ética. Iranzo et al. (2003), distinguen entre precio de los bienes y servicios turísticos, nivel de renta disponible, cambios en los hábitos de consumo y moda, la comunicación y publicidad, el tiempo disponible, las características sociodemográficas de la demanda, los factores de riesgo y los factores macroeconómicos. Ritchie y Crouch (2003:20) mencionan los recursos humanos, físicos, de capital, culturales e históricos, los conocimientos, las infraestructuras y superestructuras y el tamaño de la economía del destino. Sancho (2008:64 y ss.) enumera cinco categorías: económicos, relativos a las unidades demandantes, aleatorios, relativos a los sistemas de comercialización y relativos a la producción. Para González y Conde (2011) se encuentran los factores de tipo económico, los relativos a las unidades demandantes, los sistemas de comercialización y la satisfacción del cliente; mientras que Flores y Barroso (2012:133) hablan de factores demográficos, sociales, psicográficos o técnicos, además de los estrictamente turísticos. Existen otros muchos autores que tratan esta temática con similares agrupaciones de factores, como Blanca y Ferrís (2002:169) o Benites (2011:27).

Los factores anteriormente mencionados se encuentran conformados por variables tales como: el nivel de renta disponible, el índice de precios, la presión fiscal, el acceso a financiación, el tipo de cambio, la motivación del turista y sus características socioculturales, las formas y estilo de vida, el tiempo dedicado al ocio, la actuación de los gobiernos (en cuanto a medidas que fomenten o restrinjan u obstaculicen el turismo), acontecimientos imprevisibles como guerras o catástrofes naturales, la comunicación y publicidad, la sanidad, distancia a recorrer desde el mercado de origen, relación calidad/precio, medios de transporte disponibles, etc.

Estos factores, así como sus variables, son tratados en la literatura tanto desde un punto de vista teórico como en su aplicación a estudios e investigaciones sobre territorios concretos (a este respecto, véase Salvá, 1998:18; Gómez y López, 2002:18; García y Alburquerque, 2003:103; Molero y Valadez, 2005:86; Barroso y Flores, 2006:17; Garau, 2007; Valenzuela, 2009:9 o Guzmán et al. 2011:43; entre otros). 
Antes de finalizar este epígrafe, es necesario apuntar que, desde el enfoque integrado de la geografía económica evolutiva y relacional, se pueden señalar, más allá de los aspectos mencionados vinculados con la demanda turística, condiciones específicas evolutivas de cada destino turístico que pueden contribuir a explicar su capacidad de resiliencia a la crisis, desde la acepción adaptativa propuesta por Simmie y Martin (2010) y aplicada a diferentes territorios por autores como Martin (2012) y Sánchez (2012). No obstante, dado el reciente desarrollo teórico de este enfoque (véanse Bathlelt y Glücker, 2003 y 2011; Rehner, 2012; Domareski et al., 2014, entre otros) su aplicación al ámbito de estudio aquí tratado se realizará en posteriores investigaciones.

\section{BASES DE DATOS Y MARCO METODOLÓGICO}

Los factores determinantes de la demanda turística se pueden englobar bajo diferentes categorías, en función de la literatura económica consultada, tal y como se ha visto en el epígrafe anterior. No obstante, existen una serie de factores que aparecen mencionados de forma reiterada por los distintos autores, tales como los factores de tipo económico, de equipamiento o infraestructural, de calidad de vida y medio ambiental, además de otros de carácter intangible o de más difícil medición o cuantificación, dado el componente subjetivo del turismo (Del Campo, 1972; Acerenza, 1993; Monfort, 1998:228; Echamendi, 2001:15; Laguna y Nogués, 2001:228; Rodilla y Villaplana, 2002:17; Boullon, 2004; Kotler et al., 2004; Sancho y García, 2006; Duis, 2007:72; Barbini et al., 2009:23; Velasco, 2011:52; Carrasco, 2013:6; Muñoz, 2014:27). Es por ello que, el análisis realizado en este trabajo se sustenta sobre los factores explicativos de carácter cuantitativo ${ }^{6}$ disponibles en las diferentes fuentes estadísticas consultadas tanto pertenecientes a Eurostat (base de datos Regio y Structural business statistics (SBS)) como a la Dirección General de Análisis Macroeconómico y Economía Internacional o webs de reconocido prestigio como global-rates.com ${ }^{7}$.

De esta manera, en este trabajo se emplean variables relacionadas con los cuatro factores anteriormente mencionados cuya descripción se facilita en la Tabla 1.

Para obtener un mayor nivel de desagregación e información en el análisis, se pretende realizar un estudio a nivel regional, por lo que se ha recopilado la información correspondiente a las variables presentadas en la Tabla 1 para las 265 regiones NUTS-2 que integran la Unión Europea (UE-28) durante la actual crisis ${ }^{8}$.

6 Otros trabajos que presentan resultados robustos también se han centrado en el análisis de los factores cuantitativos, para otros sectores, ante la dificultad de medición y aproximación estadística de los componentes cualitativos. Véase, a modo de ejemplo, Gallego y Maroto (2010). En lo que al sector turístico respecta, Esteban (2004:83), menciona la mayor precisión de la capacidad explicativa de las variables económicas, además de la mayor facilidad de cuantificación de las mismas.

7 El listado de fuentes de información empleado por esta web (Bancos Centrales, institutos de estadística, organizaciones internacionales, etc.) puede consultarse en: http://es.global-rates.com/fuentes-de-informacion.aspx

8 Se ha seleccionado el año 2009 al ser el periodo para el que se proporciona en las diferentes fuentes una información más completa de las distintas variables para todas las NUTS-2. 
Tabla 1

VARIABLES ASOCIADAS A LA DEMANDA DE TURISMO
EMPLEADAS EN ESTA INVESTIGACIÓN

\begin{tabular}{|c|c|c|}
\hline VARIABLE & DESCRIPCIÓN & FUENTE \\
\hline $\begin{array}{l}\text { Comercios de bienes } \\
\text { culturales y de ocio }\end{array}$ & $\begin{array}{l}\text { Número de comercios minoristas especializados en } \\
\text { bienes culturales y de ocio. En la publicación sobre } \\
\text { estadísticas culturales de Eurostat (2011:91), se en- } \\
\text { tiende por empresas en sectores culturales las reco- } \\
\text { gidas en las secciones DE2211; DE2212; DE2213 } \\
\text { y D de la NACE Rev.1.1., no obstante, debido a la } \\
\text { adaptación a la NACE Rev.2 (a partir de 2008) a } \\
\text { efectos de esta investigación se ha utilizado como } \\
\text { indicador de la oferta cultural y de ocio la sección } \\
\text { G476 de la NACE Rev.2. }\end{array}$ & SBS \\
\hline Comercios minoristas & Número de comercios minoristas & SBS \\
\hline Camas de hospital & $\begin{array}{l}\text { Número de camas de hospital disponibles por cada } \\
100.000 \text { habitantes }\end{array}$ & Regio \\
\hline Delincuencia & $\begin{array}{l}\text { Porcentaje de población con delincuencia, violencia } \\
\text { o vandalismo a su alrededor }\end{array}$ & Regio \\
\hline $\begin{array}{l}\text { Contaminación } \\
\text { medioambiental }\end{array}$ & $\begin{array}{l}\text { Contaminación, suciedad u otros problemas } \\
\text { medioambientales (porcentaje de la población total) }\end{array}$ & Regio \\
\hline $\begin{array}{l}\text { Contaminación acús- } \\
\text { tica }\end{array}$ & $\begin{array}{l}\text { Molestias sonoras de vecinos o de la vía pública } \\
\text { (porcentaje de la población total) }\end{array}$ & Regio \\
\hline $\begin{array}{l}\text { Establecimientos } \\
\text { hoteleros y similares }\end{array}$ & $\begin{array}{l}\text { Número de hoteles, establecimientos de alojamien- } \\
\text { to turístico y otros alojamientos de corta duración, } \\
\text { campings y parkings para autocaravanas o vehículos } \\
\text { de ocio }\end{array}$ & SBS \\
\hline IPC armonizado & $\begin{array}{l}\text { Indice de precios al consumo armonizado a precios } \\
\text { constantes, } 2005=100\end{array}$ & Regio \\
\hline Tipo de cambio & $\begin{array}{l}\text { Tipo de cambio medio anual del Euro en relación } \\
\text { a la moneda nacional }(1 €=\text { número de unidades de } \\
\text { moneda nacional })\end{array}$ & $\begin{array}{l}\text { Elaboración propia } \\
\text { a partir de Eurostat, } \\
\text { Dirección General de } \\
\text { Análisis Macroeco- } \\
\text { nómico y Economía } \\
\text { Internacional y global- } \\
\text { rates.com }\end{array}$ \\
\hline Renta disponible pc & Renta disponible per cápita & Regio \\
\hline $\begin{array}{l}\text { Tasa de crecimiento } \\
\text { del VAB }\end{array}$ & $\begin{array}{l}\text { Tasa de crecimiento del Valor Añadido Bruto respec- } \\
\text { to al año precedente }\end{array}$ & Regio \\
\hline
\end{tabular}

Fuente: elaboración propia. 
Al objeto de reducir la información de partida contenida en las once variables iniciales en un menor número de dimensiones o factores subyacentes explicativos, en la siguiente sección se realiza, en primer lugar, un análisis de componentes principales (ACP) -una de las técnicas más empleadas del análisis factorial (Santesmases, 2009:395)- para, en segundo lugar, a partir de los factores identificados realizar varias estimaciones a partir de datos de panel, que permitan establecer la posible conexión entre las llegadas turísticas y algunas de las variables que, según la literatura, pueden estar condicionándolas.

Por último, una vez determinada la incidencia de los diferentes factores turísticos en las regiones europeas, se realizan tanto un análisis cluster como un análisis discriminante al objeto de conocer cómo se distribuyen estos factores entre las diferentes regiones NUTS-2 de la UE-28 y establecer, en su caso, algún tipo de relación con la respuesta del turismo en cada territorio durante la actual situación de crisis económica.

\section{ANÁLISIS DE LOS PRINCIPALES RESULTADOS}

Tal y como se mencionó en el epígrafe precedente, para alcanzar los objetivos perseguidos en esta investigación, se pretende, en primer lugar, analizar las relaciones existentes entre los valores de las variables estudiadas, para lo cual se ha realizado un ACP que permita establecer la posible conexión entre algunas de ellas (los comercios minoristas y de bienes culturales, el número de camas de hospital, la contaminación acústica y medioambiental, el nivel de delincuencia, el número de hoteles, el IPC, el tipo de cambio de la moneda nacional, la renta disponible per cápita y la tasa de crecimiento del VAB).

Previamente a la aplicación del ACP se comprueba si se encuentra justificada la factorización de la matriz de coeficientes de correlación, para ello se emplea el test de Bartlett $^{9}$. Este test rechaza la hipótesis nula de correlación significativa a un nivel del $1 \%$ $(p=0,0000)$, por lo que se considera adecuada la aplicación del ACP.

A través del ACP se obtienen cuatro factores significativos que explican, en su conjunto, el 65,82\% de la varianza (Tabla 2) ${ }^{10}$.

Se ha aplicado una rotación varimax de los ejes factoriales para facilitar la interpretación del significado de los factores. De esta manera, se observa que el primer factor retenido explica el $20,57 \%$ de la varianza y está asociado a las variables IPC (con la que presenta una alta asociación positiva), tipo de cambio, renta pc disponible y tasa de crecimiento del VAB (estas dos últimas con correlación negativa). Este factor puede identificarse con los «factores económicos» mencionados por la literatura (OMT, 1998; Sancho: 2008).

El segundo factor $(16,46 \%$ de la varianza) se encuentra asociado a las variables de contaminación, tanto acústica como medioambiental, presentando éstas las mayores cargas factoriales, positivas en este caso. Por lo tanto, este factor se puede identificar, claramente, con los «factores medioambientales» (Vera, 1997).

9 Este test parte de la hipótesis nula de equivalencia entre la matriz identidad y la matriz de coeficientes de correlación (Bartlett, 1950).

10 El criterio empleado para la determinación del número de factores significativos ha sido el de los valores propios o autovalores superior a 1, ya que es el que, por defecto, utiliza el software estadístico empleado (Dyane). En concreto, los cuatro factores extraídos presentan valores propios de 2,3303; 2,0318; 1,6795 y 1,1984, respectivamente. 


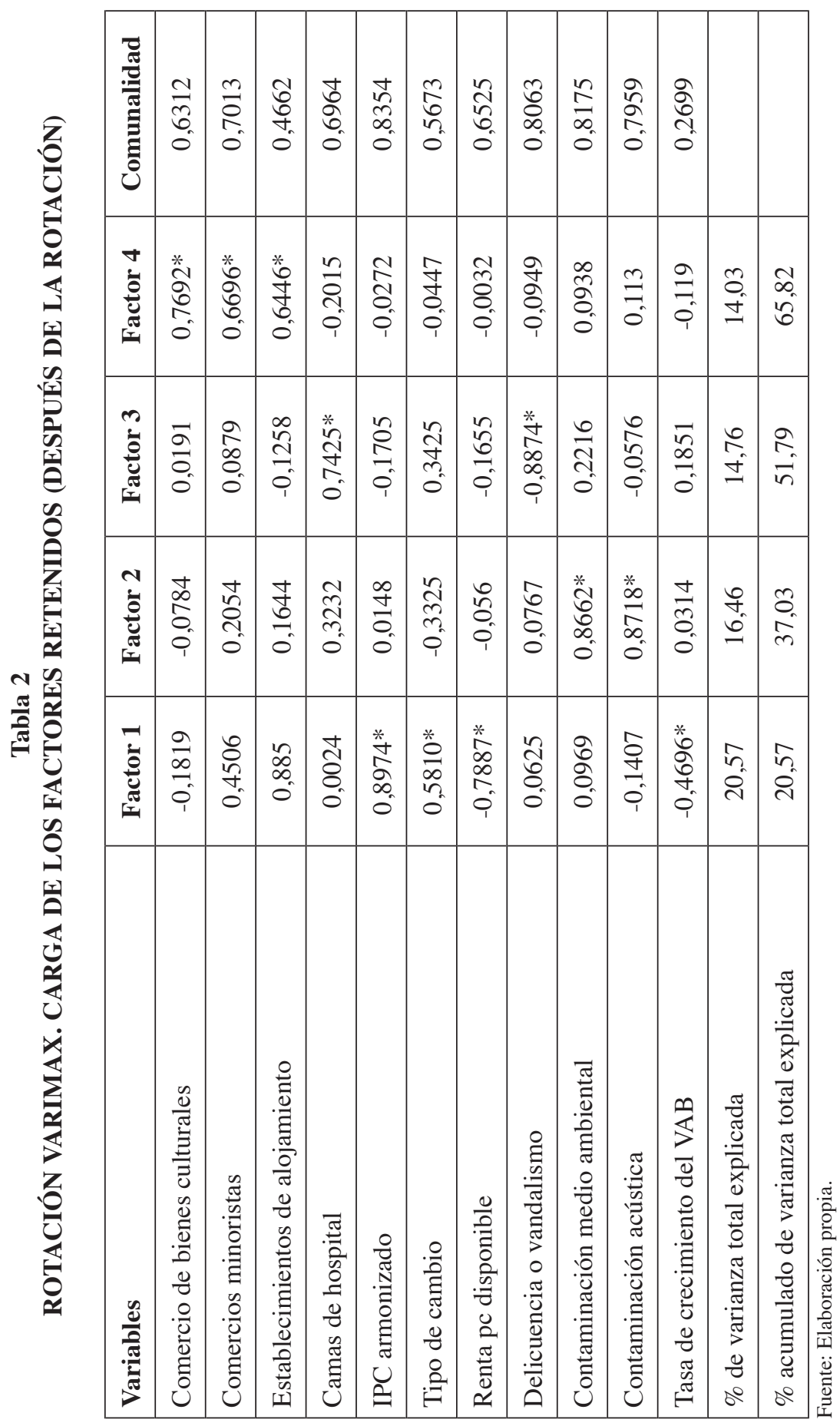


El tercero de los componentes extraídos explica el 14,76\% de la varianza y se encuentra fuertemente relacionado, de forma positiva, con el número de camas de hospital, y de forma negativa, con la delincuencia, el vandalismo o la violencia. Dados los valores de las cargas factoriales, se le puede identificar con «variables del destino» (Bull, 1994; Ritchie y Crouch, 2003) que, junto con otras, son indicativas de la calidad de vida de la población en el destino turístico.

Las cargas positivas del factor 4 -que explica en 14,03\% de la varianza total- en las variables relacionadas con el comercio y el alojamiento, refuerzan las afirmaciones planteadas por la literatura que señala a los «factores infraestructurales», entre otros, como explicativos de la atracción de la demanda turística (Ritchie y Crouch, 2003).

Seguidamente, se pretende conocer la influencia que han ejercido los cuatro factores determinantes de la demanda turística identificados a través del ACP (económicos, medioambientales, de calidad de vida e infraestructurales), sobre la llegada de turistas a través de estimaciones econométricas elaboradas a partir de datos en panel.

Los contrastes realizados muestran los resultados que se presentan en la Tabla 3. Los coeficientes de la constante y de los factores 1 y 4 son altamente significativos, y presentan los signos esperados. Sin embargo, los coeficientes de los factores 2 y 3 no son significativos, por lo que en la última regresión han sido eliminados de la especificación. Los modelos son explicativos, como así queda demostrado tanto por el coeficiente de determinación $\left(\mathrm{R}^{2}\right.$ y $\mathrm{R}^{2}$ ajustado) como por el test $\mathrm{F}$ de Snedecor. Las especificaciones realizadas por mínimos cuadrados ordinarios (MCO), con datos de panel, han sido corregidas de autocorrelación y de heteroscedasticidad mediante el procedimiento de White. Los resultados indican que la llegada de turistas ha venido favorecida por los factores 1 y 4 principalmente, es decir, por variables de tipo económico e infraestructural, más que por los factores relativos a las características medioambientales del destino o de la calidad de vida de la población.

Aunque todos ellos sean factores incidentes en la atracción turística del destino, tal y como refiere Esteban (2004:83), las variables económicas manifiestan una capacidad explicativa mucho más precisa (Esteban, 2004:81). Numerosos autores mencionan la importancia de dicho factor en este sentido, tales como Antón (1998:35), Gardella y Aguayo (2002), Aurioles et al. (2004:32).

Además, se justifica que en el análisis realizado el factor económico aparezca como uno de los principales influenciadores en la demanda turística debido a que se han utilizado para definirlo las mismas variables económicas empleadas en la mayor parte de los modelos explicativos de demanda turística, a saber, precios, tipos de cambio y renta (Morley, 1991; Crouch, 1994; Esteban, 2001).

En cuanto a las variables infraestructurales, Buisán (1997:76) demostró que la inversión en infraestructuras en transportes y comunicaciones es relevante, en el corto plazo, para explicar la evolución de los ingresos por turismo.

De entre el conjunto de factores determinantes de la demanda turística, son los factores económicos los que mayor desarrollo y análisis han tenido, en parte, fomentado por su mayor capacidad de cuantificación. No obstante, en los últimos años, es cada vez más frecuente la inclusión de la perspectiva medio-ambiental y de calidad de vida de la población, en búsqueda del desarrollo de un turismo sostenible a largo plazo y competitivo (Bosch Campubrí et al., 1998:88; Crouch \& Ritchie, 1999; Ritchie y Crouch, 2003; Mazaro y Varzin, 2008). 


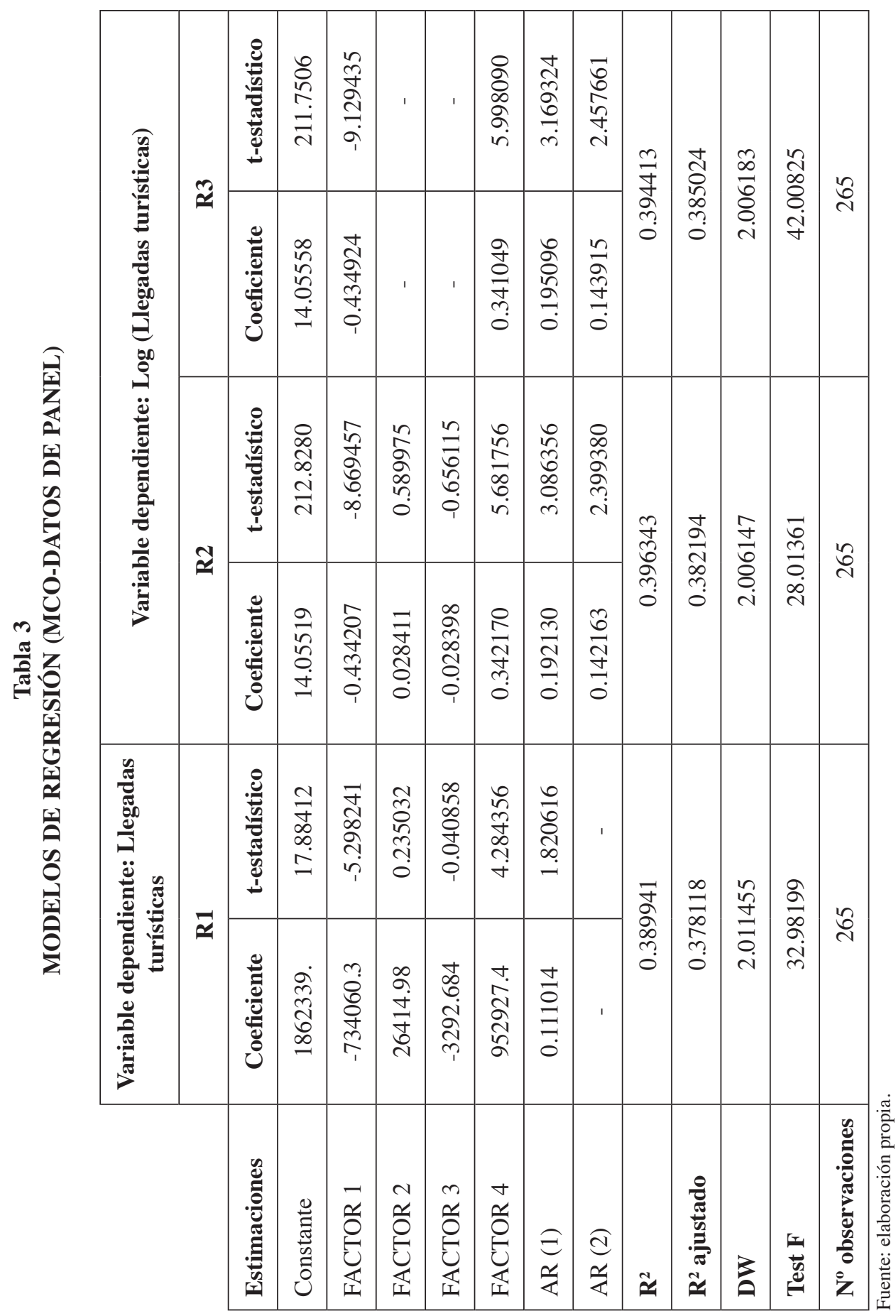


Una vez recogidas las diferentes variables de análisis en los cuatro grupos de factores que inciden en la demanda turística, y determinada la mayor incidencia en la misma de los factores de carácter económico e infraestructural o de equipamiento, frente a los factores medioambientales y de calidad de vida, se realiza un análisis cluster al objeto de conocer cómo se distribuyen estos factores entre las diferentes regiones NUTS-2 de la UE-28.

Para ello, se ha utilizado el algoritmo de Howard-Harris, dando lugar a una división en cinco grupos que reduce la suma de cuadrados total de 1.060 a 416,59, y a una explicación de la varianza total del $60,70 \%$.

Los cinco conglomerados resultantes de la aplicación del algoritmo se encuentran compuestos por 53, 8, 19, 83 y 102 NUTS-2, respectivamente.

Posteriormente, se realiza una tabulación cruzada de valores medios, aplicando la $\mathrm{F}$ de Snedecor para realizar el contraste de significación de las diferencias entre los centros de los conglomerados (Hair et al., 2005; Santesmases, 2009:352), para determinar las variables independientes cuyos valores medios muestren diferencias significativas entre los cinco grupos (Tabla 4). Se observa que la partición en cinco grupos presenta diferencias significativas al nivel del $1 \%$ en las medias de las variables seleccionadas $(p=0,0000)$ para todas las variables, de esta manera, se puede decir que cada factor presenta un comportamiento diferenciado respecto a cada uno de los conglomerados.

Tabla 4

TABULACIÓN CRUZADA DE VALORES MEDIOS

\begin{tabular}{|l|c|c|c|c|c|c|c|}
\cline { 2 - 8 } \multicolumn{1}{c|}{} & \multicolumn{5}{c|}{ GRUPOS } & \multicolumn{2}{c|}{ F-SNEDECOR } \\
\hline VARIABLES & $\mathbf{1}$ & $\mathbf{2}$ & $\mathbf{3}$ & $\mathbf{4}$ & $\mathbf{5}$ & $\mathbf{F}$ & Sig. \\
\hline FACTOR 1 & $-0,2545$ & 3,3796 & $-0,3064$ & 0,1523 & $-0,1997$ & 41,0551 & 0,0000 \\
\hline FACTOR 2 & 1,4313 & $-1,6854$ & $-0,0033$ & 0,1325 & $-0,7187$ & 151,5090 & 0,0000 \\
\hline FACTOR 3 & 0,6738 & 1,8111 & $-0,1021$ & $-1,1672$ & 0,4767 & 155,1423 & 0,0000 \\
\hline FACTOR 4 & $-0,3008$ & 0,0409 & 2,8529 & $-0,2952$ & $-0,1381$ & 113,7321 & 0,0000 \\
\hline
\end{tabular}

Fuente: elaboración propia.

Finalmente, se aplica un análisis discriminante con objeto de validar si los grupos obtenidos están suficientemente diferenciados en función de las variables independientes utilizadas (Fernández et al., 2004:8, Quijano, 2009:55; Santesmases, 2009:447). En este sentido, el indicador lambda de Wilks toma un valor muy próximo a cero $(0,0130)$, lo que indica que la variabilidad total es debida a las diferencias entre grupos. El $p$-valor asociado al estadístico resulta estadísticamente significativo a un nivel del $1 \%(p=0,0000)$, por lo que se rechaza la hipótesis nula de igualdad de medias entre los grupos y la información aportada por las respectivas funciones discriminantes se considera estadísticamente significativa. El test de Bartlett también permite rechazar la hipótesis nula de no correlación significativa a un nivel de significación del $1 \%$, por lo que es adecuado calcular la matriz de confusión del análisis discriminante con los grupos del análisis cluster. 
Los resultados de la matriz de confusión muestran que existe un porcentaje de asignaciones correctas del $97,74 \%$.

A partir del análisis realizado se pueden, por lo tanto, clasificar las diferentes regiones europeas NUTS-2, en cinco grupos en función de los factores que influyen en su demanda turística. Con la finalidad de facilitar la comprensión de la distribución de las diferentes NUTS-2 en cada uno de los cinco clusters, desde un punto de vista de distribución territorial, se elabora el mapa representado en la Figura 1.

\section{Figura 1 \\ CLASIFICACIÓN DE LAS REGIONES \\ NUTS-2 DE LA UE-28 SEGÚN EL ANÁLISIS CLUSTER}

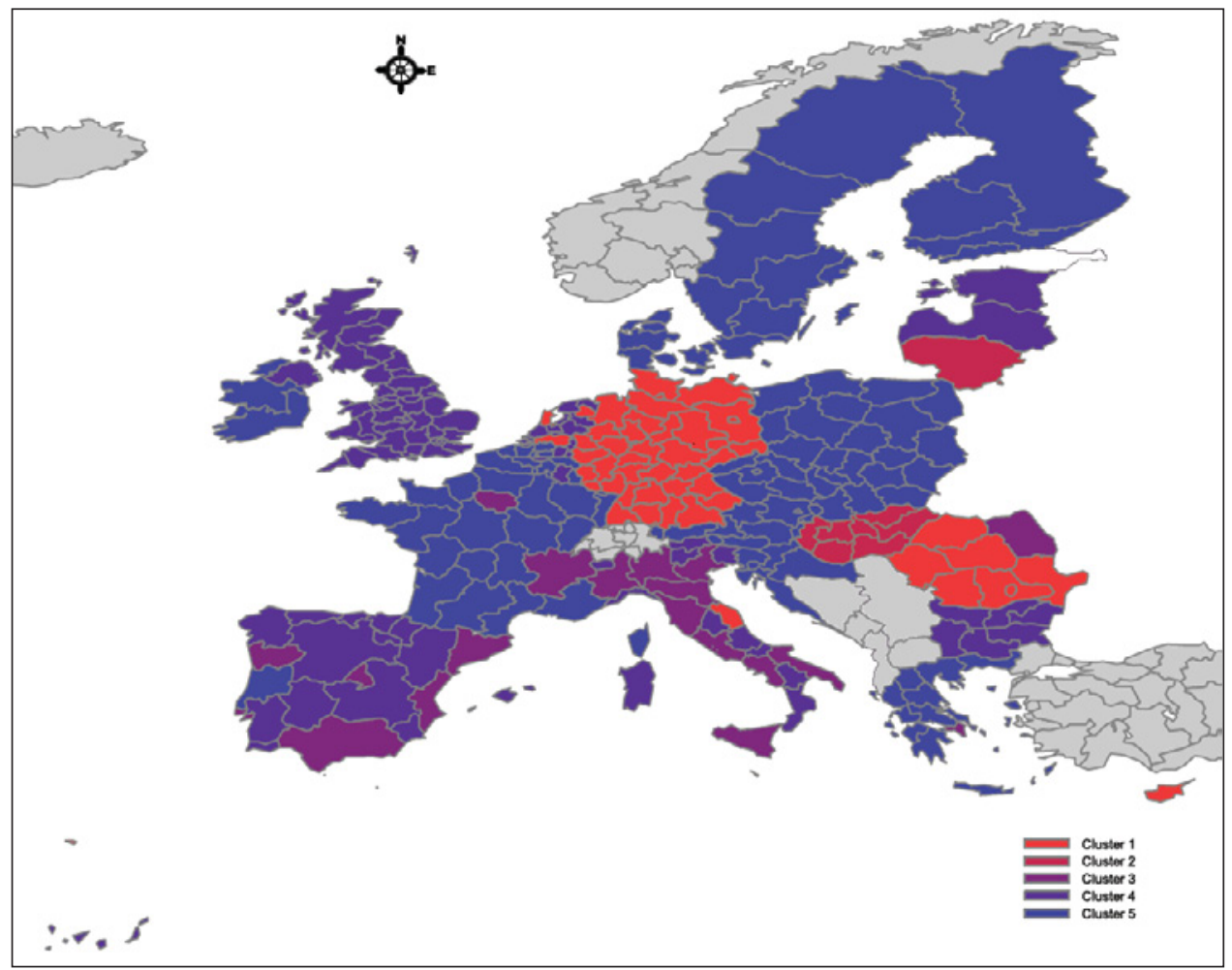

Fuente: elaboración propia.

En la Fig. 1 se observa, por una parte, que el grupo 3 se encuentra integrado por regiones de gran importancia turística, tales como Andalucía, Lisboa, Île-de-France (área metropolitana de París) o la región del Lazio (cuya capital es Roma), entre otras. Este conjunto de regiones poseen los mayores valores medios en lo que al factor económico e infraestructural respecta (los establecidos anteriormente como más determinantes en la llegada de turismo). 
Por otra parte, también destaca el comportamiento del cluster 2, integrado únicamente por ocho regiones que se corresponden íntegramente con los países de Hungría (siete regiones) y Lituania (formado por una única región). Este cluster presenta los mejores valores en cuanto al factor medioambiental, aunque son los peor situados en las variables que integran el factor económico.

Las regiones integrantes del cluster 1 se corresponden con Alemania, la mayor parte de Rumanía (siete de sus ocho regiones), Chipre, Malta así como dos islas portuguesas, una región italiana y tres de los Países Bajos. Presentan los peores indicadores infraestructurales y medioambientales del conjunto de regiones analizadas.

En último lugar, la mayor parte de las regiones europeas se sitúan en los grupos 4 y 5 (que representan casi un $70 \%$ del total de regiones de la UE), en las que no es de destacar ninguno de los cuatro factores turísticos analizados en este trabajo, en particular.

Por lo tanto, a raíz del análisis realizado se puede decir que la presencia de los cuatro factores identificados como incidentes en las llegadas turísticas no es homogénea en las diferentes NUTS-2, coincidiendo una mayor presencia de los más relevantes (económicos e infraestructurales) en las regiones de mayor tradición turística.

Es decir, regiones turísticamente más maduras, que coinciden con regiones de gran desarrollo, con elevados niveles de renta per cápita e infraestructuras hoteleras, presentan un mejor comportamiento en cuanto a atracción turística durante la crisis que otras regiones de rápido crecimiento turístico en época de bonanza pero cuyos factores económicos e infraestructurales no se encuentran en los mismos niveles que las anteriores.

El desarrollo local es una estrategia que facilita la salida de la actual crisis (Vázquez, 2009:124 y ss.). Entre las medidas necesarias para el proceso de desarrollo, este autor menciona la «construcción de equipamientos urbanos e infraestructuras» (p.128) y la «conservación y mejora del medio ambiente y del patrimonio histórico» (p. 129), entre otras. Además, este mismo autor cita una serie de medidas estructurales para activar la economía real anunciadas por el FMI en 2009. Se observa que, entre ellas, destacan medidas que atañen a los cuatro factores objeto de estudio. A saber, medidas económicas (reducciones en el impuesto sobre la renta de las personas físicas, en los impuestos indirectos y en el impuesto de sociedades); medidas concernientes a las infraestructuras (aumento del gasto público en infraestructuras de transporte y comunicaciones); medidas medio ambientales (desarrollo de las energías renovables solar y eólica); medidas que afectan a la calidad de vida (aumento de la dotación de hospitales y médicos, mejora de la formación, ayudas a los parados, pobres y pensionistas, etc.). En definitiva, cuanto mejor sea la posición del destino en lo que respecta a los cuatro factores analizados (económicos, infraestructurales, medioambientales y de calidad de vida), mayor será su grado de desarrollo, y mejor su capacidad de resistencia a la crisis. Según se ha comprobado, estas circunstancias confluyen en las regiones maduras, por eso su crecimiento turístico aumenta en época de crisis mientras que se ralentiza en las regiones emergentes.

\section{CONCLUSIONES}

A lo largo del presente artículo se ha realizado una breve revisión teórica sobre la evolución del turismo en Europa tanto antes como durante la actual situación de crisis, 
así como una revisión de la literatura sobre las variables con incidencia en la demanda turística. Además, este marco teórico se ha complementado con la aplicación de diferentes metodologías de análisis (análisis de componentes principales, de regresión, clúster y discriminante) con la finalidad de dar respuesta a los objetivos planteados en el trabajo.

En base a todo lo anterior, las principales conclusiones alcanzadas se pueden resumir en los siguientes puntos:

- Europa es el principal destino turístico mundial, destacando como más visitados territorios turísticamente maduros, situados, fundamentalmente, en países como Italia, Francia, Grecia o España, entre otros. El crecimiento de las llegadas turísticas en estos destinos maduros antes de la actual crisis ha sido muy inferior al presentado por las regiones de Europa Central y Oriental, sobre todo, a partir de la quinta ampliación de la UE, con la incorporación de la mayor parte de los países de la denominada «Europa del Este». No obstante, durante la crisis, este comportamiento se invierte, siendo mucho más pronunciado el descenso en el ratio de crecimiento de estos países emergentes, a pesar de que, en algunos de ellos, como Hungría o la República Checa, la mayor tasa de crecimiento de su turismo interno durante la crisis ha permitido compensar, en parte, la ralentización en el crecimiento de las llegadas turísticas internacionales.

- Se ha identificado la existencia de relación entre algunas de las distintas variables mencionadas por la literatura como determinantes de la demanda turística, dando lugar a cuatro grupos de factores incidentes en la misma, de orden económico, infraestructural, de calidad de vida y medioambiental. De todos ellos, se determina que son los dos primeros los de mayor incidencia en las llegadas turísticas. Aunque, según los resultados del presente análisis, los factores medio ambiental y de calidad de vida no se configuran aún como tan determinantes en la atracción turística como los económicos e infraestructurales, su creciente auge y las mejoras en su posibilidad de cuantificación y medición pueden conllevar un importante salto cualitativo en su posicionamiento en los futuros modelos de demanda turística.

- La presencia de estos cuatro factores no es homogénea en las diferentes NUTS-2, demostrando que en las regiones turísticamente más maduras se dan unos valores más elevados de los factores más relevantes (económicos e infraestructurales). Hecho este que puede contribuir a explicar que, durante la crisis, estas regiones hayan experimentado un descenso de su crecimiento turístico no tan pronunciado como el de las regiones emergentes (que, anteriormente habían ostentado incluso tasas de crecimiento por encima del $10 \%$ en algunos casos), demostrando así, un comportamiento turístico mucho más estable (en época de bonanza y de crisis) y su consolidación en el sector. No obstante, los cuatro factores analizados son elementos del desarrollo regional por lo que un aumento de las inversiones en estos ámbitos y una elaboración de políticas estratégicas dirigidas hacia el adecuado fomento de los mismos pueden contribuir al aumento de la demanda turística del destino así como a una mejor capacidad de adaptación ante cambios en el ciclo económico. 
Los autores son conscientes de las limitaciones que presenta este artículo, es por ello que, esta investigación se presenta con carácter exploratorio como una primera aproximación a la temática analizada con el objeto de que las conclusiones alcanzadas abran una vía de investigación y se configuren como un primer paso para continuar analizando aspectos en los que es necesario profundizar.

De esta manera, se pretende en la continuidad del estudio ir salvando las limitaciones encontradas y avanzando en la investigación mediante el incremento del número de variables utilizadas, la implementación de análisis dinámicos para el periodo de crisis, la ampliación del periodo muestral, la utilización de nuevas fuentes estadísticas y de una aproximación evolucionista a la geografía regional europea, distintos métodos de investigación, la elaboración de variables que permitan la cuantificación y una mejor aproximación a los conceptos teóricos sobre todo de carácter más subjetivo, entre otros.

\section{BIBLIOGRAFÍA}

ACERENZA, M.A. (1993): Promoción turística: un enfoque metodológico. México. Trillas.

AGARWAL, S. (2002): «La reconversión del turismo costero. El ciclo de vida del destino turístico costero». Annals of Tourism Research en español, $\mathrm{n}^{\circ}$ 4(1), 1-36.

AGUILO, E., ALEGRE, J. y SARD, M. (2005): «The persistence of the sun and sand tourism model». Tourism Management, $\mathrm{n}^{\circ}$ 26, 219-231.

ÁLVAREZ SOUSA, A. (2005): «La contribución del turismo al desarrollo integral de las sociedades receptoras. Aspectos teórico-metodológicos». Política y Sociedad, $\mathrm{n}^{\circ}$ 42(1), 57-84.

ANDRÉS SARASA, J.L. (2000): «Aportaciones básicas del turismo al desarrollo rural». Cuadernos de Turismo, $\mathrm{n}^{\circ}$ 6, 45-60.

ANTÓN CLAVÉ, S. (1998): «La urbanización turística. De la conquista del viaje a la reestructuración de la ciudad turística». Documents d'Anàlisi Geogràfica, nº 32, 17-43.

ARMESTO LÓPEZ, X.A. y GÓMEZ MARTÍN, B. (2004): «Productos agroalimentarios de calidad, turismo y desarrollo local: el caso del Priorat». Cuadernos Geográficos, $\mathrm{n}^{\mathrm{o}}$ 34(1), 83-94.

AURIOLES, J., FERNÁNDEZ, C. y MANZANERA, E. (2004): El medio y el largo plazo en el turismo español. En AURIOLES MARTÍN, J. (coord.): Las nuevas formas del turismo. Almería: Instituto de Estudios de Cajamar, 15-38.

AURIOLES, J. (2012): «Crisis económica y cambios en el turismo». Mediterráneo Económico, $\mathrm{n}^{\circ}$ 20, 99-114.

BARBINI, B.; ROLDÁN, N.; CACIUTTO, M. y CRUZ, G. (2009): «Modelos de desarrollo y visiones sobre el turismo. Aportes de la teoría del capital social al paradigma alternativo». Aportes y transferencias, $\mathrm{n}^{\circ} 1(13), 11-26$.

BARROSO GONZÁLEZ, M. O. y FLORES RUIZ, D. (2006): «La competitividad internacional de los destinos turísticos: del enfoque macroeconómico al enfoque estratégico». Cuadernos de Turismo, $\mathrm{n}^{\circ}$ 17, 7-24.

BARTLETT, M.S. (1950): «Tests of significance in Factor Analysis». British Journal of Psychology, $\mathrm{n}^{\mathrm{o}}$ 3, 77-85. 
BATHELT, H. y GLÜCKLER, J. (2003): «Toward a relational economic geography». Journal of Economic Geography, $\mathrm{n}^{\circ}$ 3, 117-144.

BATHELT, H. y GLÜCKLER, J. (2011): The Relational Economy: Geographies of Knowing and Learning. Oxford:Oxford University Press.

BENITES CUBA, M. (2011): Factores determinantes del desarrollo turístico del distrito de Yura. Tesis para el Grado de Maestro. Perú. Universidad Nacional de San Agustín de Arequipa. BLANCA, V. y FERRÍS, C. (2002): «Las infraestructuras turísticas y los equipamientos en los espacios naturales y rurales» en Turismo en espacios naturales y rurales II (Viñals, M. J.). Valencia. Edit. Universidad Politécnica de Valencia, 167-192.

BOSCH CAMPUBRÍ, R.; MARCO, L. P.; CABADO, J. S. y RIERA, F. V. (1998): Turismo y medio ambiente. Madrid: Centro de Estudios Ramon Areces.

BOULLON, R. (2004): Marketing turístico: una perspectiva desde la planificación (2a ed.). Buenos Aires. Ediciones Turísticas.

BUISÁN, A. (1997): «Exportaciones de turismo y competitividad». Revista de Economía Aplicada, $\mathrm{n}^{\mathrm{0}} 13,65-81$.

BULL, A. (1994): La Economía del Sector Turístico. Madrid. Alianza Editorial.

BUTLER, R.W. (1980): «The concept of a tourist area cycle of evolution: implications for management of resources». The Canadian Geographer, vol. XXIV, I, 5-12.

BUTLER, R.W. (2006a): The tourist area life cycle. Applications and Modifications, vol. I, Clevedon. Channel View.

BUTLER, R.W. (2006b): The tourist area life cycle. Conceptual and Theoretical Issues, vol. II, Clevedon. Channel View.

CARRASCO FERNÁNDEZ, S. (2013): Procesos de gestión de calidad en hostelería y turismo. España. Ediciones Paraninfo.

COSCUBIELA CONESA, J. (2010): «Causas y lecciones ignoradas de la crisis». Mediterráneo económico, $\mathrm{n}^{\circ} 18,345-364$.

CROUCH, G. (1994): «The Study of International Tourism Demand: A Survey of Practice». Journal of Travel Research, $\mathrm{n}^{\circ} 32(4), 41-55$.

CROUCH, G. I. y RITCHIE, B. J. R. (1999) : «Tourism, competitiveness, and societal prosperity». Journal of Business Research, $\mathrm{n}^{\circ} 44(3), 137-152$.

CUADRARO-ROURA, J.R. y MAROTO-SÁNCHEZ, A. (2012): «Análisis del proceso de especialización regional en servicios en España». EURE, vol. 38, n 114, 5-34.

DEL CAMPO Y FRANCÉS, A. (1972): «El sentimiento estético, soporte subjetivo del turismo». Estudios Turísticos, $\mathrm{n}^{\circ} 36,239-246$.

DELGADO VIÑAS, C., GIL DE ARRIBA, C., HORTELANO MÍNGUEZ, L.A. y PLAZA GUTIÉRREZ, J.I. (2003): «Turismo y desarrollo local en algunas comarcas de la montaña cantábrica: recursos y planificación». Cuadernos de Turismo, n ${ }^{\circ}$ 12, 7-34.

DIRECCIÓN GENERAL DE ANÁLISIS MACROECONÓMICO Y ECONOMÍA INTERNACIONAL. Ministerio de Economía y Competitividad. Secretaría de Estado de Economía y Apoyo a la empresa. http://serviciosweb.meh.es/apps/dgpe/ (Consultado el 13 de enero de 2015).

DOMARESKI RUIZ, T. C., CHIM MIKI, A.F. y GÂNDARA, J.M. (2014): «A geografia econômica evolutiva como perspectiva de análise da dinâmica dos destinos turísticos». Caderno Virtual de Turismo, n 14(3), 316-336. 
DORTA RODRÍGUEZ, A. (2011): Crisis económica y cierre de establecimientos alojativos en destinos turísticos consolidados. El caso de Puerto de la Cruz (Tenerife). En Espacios y destinos turísticos en tiempos de globalización y crisis. Madrid. Vol. II, AGE, 183-197.

DOUGLAS, N. (1997) : «Applying the life cycle model to Melanesia». Annals of Tourism Research, $\mathrm{n}^{\circ} 34(1), 1-22$.

DUIS, U. (2007): «La valorización cultural, social y turística de los recursos culturales y naturales como instrumento para la planificación turística, la conservación del paisaje cultural cafetero y el desarrollo sostenible del territorio turístico». Anuario Turismo y Sociedad, $n^{\circ} 8,69-79$.

ECHAMENDI LORENTE, P. (2001): «La capacidad de carga turística. Aspectos conceptuales y normas de aplicación». Anales de Geografía de la Universidad Complutense, $\mathrm{n}^{\mathrm{o}} 21,11-30$.

ESTEBAN TALAYA, A. (2001): Tendencias recientes de la demanda turística. En BUENDÍA, J.B. y COLINO, J.: Turismo y Medio Ambiente. Madrid: Cívitas, 193-213.

ESTEBAN TALAYA, A. (2004): «Modelos de la demanda turística en España: segmentación por país de procedencia». Mediterráneo Económico, nº 5, 81-101.

EUROSTAT: http://epp.eurostat.ec.europa.eu/portal/page/portal/eurostat/home/ (Consultado el 19 de marzo de 2015).

EUROSTAT (2011): Cultural statistics. Luxemburgo. Eurostat Pocketbooks, Publications Office of the European Union.

FERNÁNDEZ, S., RODEIRO, D. y RUZO, E. (2004): «Análisis de la oferta de las universidades gallegas». Working Paper Series Economic Development, $\mathrm{n}^{\circ}$ 82, 1-23.

FLORES RUIZ, D. y BARROSO GONZÁLEZ, M.O. (2012): «La demanda turística internacional. Medio siglo de evolución». Revista de Economía Mundial, n 32, 127-149.

FONDO MONETARIO INTERNACIONAL (FMI) (2009): «World Economic Crisis. Stimulus Measures Bolstering Demand Amid Crisis ». IMF Survey Magazine: Policy, $\mathrm{n}^{\mathrm{o}}$ 6. International Monetary Fund. Washington.

GALLEGO MARTÍNEZ-ALCOCER, J. y MAROTO SÁNCHEZ, A. (2010): «Análisis de la localización regional de los servicios intensivos en conocimiento a nivel europeo». Investigaciones Regionales, $\mathrm{n}^{\circ} 17,71-92$.

GARAU TABERNER, J. (2007): «Propuesta de dos índices para la medición de la competitividad de los destinos de sol y playa del Mediterráneo: avance de resultados desde el punto de vista de la demanda». Revista de Análisis Turístico, no 4(2), 50-67.

GARCÍA ANDREU, H. (2014): «El círculo vicioso del turismo residencial: análisis de los factores locales del boom inmobiliario español». PASOS, Revista de Turismo y Patrimonio Cultural, vol. 12 (2), 395-408.

GARCÍA SÁNCHEZ, A. y ALBURQUERQUE GARCÍA, F. J. (2003): «El turismo cultural y el de sol y playa: ¿sustitutivos o complementarios?». Cuadernos de Turismo, $\mathrm{n}^{\mathrm{o}} 11,97-105$.

GARDELLA, R. J., y AGUAYO, E. (2002): Análisis econométrico de la demanda turística internacional en la CAN. Compostela: Universidad de Santiago de Compostela, 1-17.

GARZÓN BECKMANN, A. (2011): Condicionantes de la competitividad turística grancanaria. Sevilla. Círculo Rojo. 
GLOBAL-RATES.COM: http://es.global-rates.com/ (Consultado el 13 de enero de 2015).

GÓMEZ MARTÍN, B. y LÓPEZ PALOMEQUE, F. (2002): Regionalización turística del mundo. Barcelona. Edicions Universitat Barcelona.

GONZÁLEZ ALATORRE, E.A. y CONDE PÉREZ, E.M. (2011): «Procedimiento para medir la demanda turística en un destino». TuryDes, no 4 (11). http://www.eumed.net/ rev/turydes/11/gacp.html (Consultado el 24 de noviembre de 2014).

GONZÁLEZ, R. y MANTECÓN TERÁN, A. (2014): «Turismo y negocio inmobiliario: la crisis de un modelo de desarrollo. Tres estudios de casos de Canadá, Argentina y España». Estudios y Perspectivas en Turismo, vol. 23 (4), 685-705.

GÜEMEZ RICALDE, F.J.; ZAPATA SÁNCHEZ, J.L. y FORSTER HOJER, R.A. (2013): «Neuroeconomía y turismo en tiempos de crisis». Revista Global de Negocios, vol. 1 (1), 13-25.

GUZMÁN SORIA, E.; DE LA GARZA CARRANZA, M. T.; REBOLLAR REBOLLAR, S.; HERNÁNDEZ MARTÍNEZ, J. y GARCÍA SALAZAR, J. A. (2011): «Factores determinantes de la demanda internacional del turismo en México». GCG, $\mathrm{n}^{\circ} 5(3), 30-49$.

HAIR J.F., ANDERSON, R.E., TAHTAM, R.L. y BLACK, W. (2005): Análisis multivariante ( $6^{\mathrm{a}}$ ed.). Madrid. Prentice Hall.

HOVINEN, G. R. (2002) : «Revisiting the destination lifecycle model». Annals of Tourism Research, $\mathrm{n}^{\circ}$ 29(1), 209-230.

IRANZO, J.E.; PEDROSA, M.; SALIDO, J.; IZQUIERDO, G.; MARTÍNEZ DE DIOS, J. y DÍAZ, S. (2003): «La demanda de turismo», en Iranzo, J.E. et al.: La estructura económica de los mercados turísticos, Instituto de Estudios Económicos, Madrid, 59-93.

KNOWLES, T. y CURTIS, S. (1999) : «The market viability of European mass tourist destinations: a post-stagnation life-cycle analysis». The International Journal of Tourism Research, $\mathrm{n}^{\circ} 1,87-96$.

JIMÉNEZ GARCÍA, M. (2011): Política turística común y Co-Country-branding: dos apuestas turísticas para la Unión Europea. Alemania. Editorial Académica Española.

KOTLER, P.; BOWEM, J. y MAKENS, J. (2004): Marketing para turismo (3 ${ }^{\mathrm{a}}$ ed.). España. Pearson.

LAGUNA MARÍN-YASELI, M. y NOGUÉS BRAVO, D. (2001): «La potencialidad turística del medio natural en el LIC de las Sierras Ibéricas riojanas mediante evaluación multicriterio». Zubía Monográfico, $\mathrm{n}^{\circ}$ 13, 227-240.

LILLO BAÑULS, A.; RAMÓN RODRÍGUEZ, A.B. y SEVILLA JIMÉNEZ, M. (2007): «El capital humano como factor estratégico para la competitividad del sector turístico». Cuadernos de Turismo, ${ }^{\circ}$ 19, 47-69.

LUNDTORP, S. y VANHILL, S. (2001): «La teoría del ciclo de vida del destino turístico.: Procesos de generación y estimación». Annals of tourism research en español, $\mathrm{n}^{\circ} 3(2)$, 364-383.

MARTIN, R. (2012): «Regional economic resilience, hysteresis and recessionary shocks». Journal of Economic Geography, n ${ }^{\circ}$ 12, 1-32.

MAZARO, R. M., Y VARZIN, G. (2008): «Modelos de Competitividad para Destinos Turísticos en el Marco de la Sostenibilidad». Revista de Administração Contemporânea, $\mathrm{n}^{\mathrm{o}} 12(3), 789-809$. 
MOLERO ZAYAS, J. y VALADEZ SÁNCHEZ, P. (2005): «Factores determinantes de la competitividad de los servicios: la importancia de la innovación». ICE, $\mathrm{n}^{\circ}$ 824, 71-91.

MONFORT MIR, V.M. (1998): «Benidorm y Peñíscola: competitividad comparada». Revista Valencia de Estudios Autonómicos, nº 25 (4), 217-243.

MONTI, E. (2011): «La crisis económica internacional de 2008 y el turismo: efectos y medidas de respuesta en Rio Grande do Norte, Brasil». Investigaciones Turísticas, $\mathrm{n}^{\circ}$ 1, 93-106.

MOORE, W. y WHITEHALL, P. (2005): «El ciclo de vida del área turística y los modelos de cambios de régimen». Annals of tourism research en español, $\mathrm{n}^{\circ}$ 7(1), 48-64.

MORA JIMÉNEZ, H. y MORALES RAMOS, R. (2010): «La crisis financiera estadounidense: principales efectos macroeconómicos en la economía costarricense en 2008 y 2009». Revista Nacional de Administración, nº1, 37-54.

MORALES RAMOS, R. (2009): «El impacto de la crisis económica mundial sobre la economía costarricense: los efectos macroeconómicos». Economía y Sociedad, $\mathrm{n}^{\circ}$ 35-36, 61-73.

MORALES ZÚÑIGA, L.C. (2011): «Crisis económica, desarrollo turístico y trabajo: el caso de los trabajadores de la comunidad de los Pargos, Guanacaste». Revista de Ciencias Económicas, vol. 29, nº 1, 385-399.

MORENO GIL, S. y PICAZO PERAL, P. (2012):»Difusión de la investigación científica en revistas de turismo realizada por instituciones españolas», Revista de Análisis Turístico, $\mathrm{n}^{\circ}$ 14(2), 33-52.

MORILLO, M. (2009): «Capacidad de resistencia del turismo en épocas de crisis». Saber, vol. 21, 292-305.

MORLEY, C. (1991): «Modeling International Tourism Demand: Model Specification and Structure». Journal of Travel Research, $\mathrm{n}^{\circ}$ 30(1), 40-44.

MUÑOZ ESCALONA, F. (1992): «Turismo y desarrollo». Estudios Turísticos, n ${ }^{\circ} 115$, 23-44.

MUÑOZ ESCALONA, F. (2014): La resistible complejidad del turismo. En: MONTERRUBIO CORDERO, J. C. y LÓPEZ LÓPEZ, A. (Coords.): De la dimensión teórica al abordaje empírico del turismo en México. Perspectivas multidisciplinarias. Primera edición, 21-36. UNAM, México.

NEL-LO ANDREU, M. y PÉREZ ALBERT, Y. (2007): «La política turística en Panamá. Resultados y perspectivas», Cuadernos de Turismo, n 20, 199-221.

OREJA RODRÍGUEZ, J. R., PARRA-LÓPEZ, E. y YANES-ESTÉVEZ, V. (2008): «The sustainability of island destination: Tourism area life cycle and teleological perspectives, the case of Tenerife». Tourism Management, $\mathrm{n}^{\circ}$ 29, 53-65.

ORGANIZACIÓN MUNDIAL DEL TURISMO (OMT) (1998): Introducción al turismo. Madrid. Organización Mundial del Turismo.

ORGANIZACIÓN MUNDIAL DEL TURISMO (OMT) (2010): Panorama OMT del Turismo Internacional. OMT. http://www2.unwto.org/es (Consultado el día 21 de noviembre de 2014).

ORGANIZACIÓN MUNDIAL DEL TURISMO (OMT) (2014): Tourism Highlights, 2014 Edition, UNWTO. 
PEDREÑO, A. y MONFORT, V. (1996): Introducción a la Economía del Turismo en España. Madrid. Editorial Civitas.

PERELLI, O. (2010): «Turismo español. ¿Y si no hubiera habido crisis?». Economistas, año XXVIII, extra, 100-111.

PERICHI, C. C. (2000): Centros históricos y turismo en América Latina. Una polémica de fin de siglo. En CARRIÓN, F. (ed.): Desarrollo cultural y gestión en centros históricos, 105-120. Ecuador: Flacso.

PRATS, LL. (2011): «El patrimonio en tiempos de crisis». Revista andaluza de antropología, no 2, 68-85.

PULIDO FERNÁNDEZ, J. I. (Coord.) (2009): «El turismo español en tiempos de crisis. Una perspectiva empresarial». Revista de Análisis Turístico, n 7, 66-76.

PUNZO, L.F. (2002): «Sostenibilidad del turismo y desarrollo económico local: el caso de la región de Toscana». Económica, no 4(2), 193-222.

QUIJANO PONCE DE LEÓN, A. (2009): Trabajo de sistemas de investigación de mercados. Argentina. El Cid Editor.

REHNER, J. (2012): «Territorios corporativos: una reflexión desde la geografía económica para evitar la axiomatización de los discursos». Revista de Geografía Espacios, $\mathrm{n}^{\mathrm{o}} 2(4), 27-47$.

RITCHIE, J.R.B. y CROUCH, G.I. (2003): The competitive destination. A sustainable tourism perspective. Oxon, Reino Unido. CABI Publishing.

RODILLA, M. y VILLAPLANA, J. (2002): «Turismo y medio ambiente» en Turismo en espacios naturales y rurales II (Viñals, M. J.). Valencia. Universidad Politécnica de Valencia, 7-46.

RODRÍGUEZ ANTÓN, J.M. y ALONSO ALMEIDA, M.M. (Coords.) (2009): Nuevas tendencias y retos en el sector turismo. Un enfoque multidisciplinar. Madrid. Delta.

RODRÍGUEZ NUÑO, V. (2005): «Índice de especialización sectorial en los Estados miembros de la Unión Europea en 2003». Boletín Económico de ICE, nº 2839, 27-33.

RODRÍGUEZ-TOUBES MUÑIZ, D. y FRAIZ BREA, J.A. (2011): «Herramientas de coordinación para la gestión de crisis en el turismo». International Journal of Safety and Security in Tourism/Hospitality, $\mathrm{n}^{\circ} 1,1-15$.

ROSSELLÓ NADAL, J. AGUILÓ PÉREZ, E. y RIERA FONT, A. (2005): «Un modelo dinámico de demanda turística para Baleares». Revista de Economía Aplicada, $\mathrm{n}^{\circ}$ 39, 5-20.

SALVÁ TOMÁS, P.A. (1998): «Los modelos de desarrollo turístico en el Mediterráneo». Cuadernos de Turismo, $\mathrm{n}^{\circ}$ 2, 7-24.

SÁNCHEZ HERNÁNDEZ, J.L. (2012): Sensibilidad y resiliencia de las regiones españolas durante las crisis económicas (1976-2011). V Jornadas de Geografía Económica AGE, Univ. de Girona.

SÁNCHEZ, R.R.; DÍAZ, B.R., y BERNIER, E.J.T. (2012): «Efectos de la crisis en el sector turístico español». Cuadernos de ciencias económicas y empresariales. Papeles de trabajo, $\mathrm{n}^{\circ} 40,1-151$.

SANCHO, A. (Dir.) (2008): Introducción al turismo, OMT.

SANCHO PÉREZ, A. y GARCÍA MESANAT, G. (2006): «¿Qué indica un indicador? Análisis comparativo en los destinos turísticos». Revista de Análisis Turístico, nº 2(2), 69-85. 
SANTESMASES MESTRE, M. (2009): DYANE Versión 4. Diseño y análisis de encuestas en investigación social y de mercados. Madrid. Pirámide.

SIMMIE, J. y MARTIN, R. (2010): «The economic resilience of regions: towards an evolutionary approach». Cambridge Journal of Regions, Economy and Society, n 3, 27-43.

SOARES, J.C., GANDARA, J.M. y IVARS BAIDAL, J. (2012): «Indicadores para analizar la evolución del ciclo de vida de los destinos turísticos litorales». Investigaciones Turísticas, $\mathrm{n}^{\circ}$ 3, 19-38.

TOCQUER, G. y ZINS, M. (1987): Marketing du tourisme. Montreal. Gaëtan Morin Éditeur.

TORRES BERNIER, E. (1994): «Turismo y desarrollo regional». Papers de Turisme, $\mathrm{n}^{\circ}$ 14-15, 95-102.

TROITIÑO VINUESA, M.A. (1998): «Turismo y desarrollo sostenible en ciudades históricas». Ería: Revista cuatrimestral de geografía, $\mathrm{n}^{\circ}$ 47, 211-228.

VALENZUELA RAMÍREZ, I.E. (2009): «Perspectivas del sector turismo en un contexto de crisis internacional». Temas de Análisis, n 5(22), 7-12.

VÁZQUEZ BARQUERO, A. (2009): «Desarrollo local. Una estrategia para tiempos de crisis». Apuntes del CENES, $\mathrm{n}^{\circ}$ 47, 117-132.

VELASCO ROMERA, I. (2011): El papel de las tarjetas postales en la conformación de la imagen del destino turístico. El caso de la ciudad de Segovia. Colmenarejo, Madrid. XII Coloquio de Geografía del Turismo, Ocio y Recreación, Asociación de Geógrafos Españoles. http://hdl.handle.net/10016/16447 (Consultado el 25 de noviembre de 2014).

VERA REBOLLO, J. F. (Coord.) (1997): Análisis territorial del turismo: una nueva geografía del turismo. Barcelona. Ariel Geografía.

VERA REBOLLO, F. y MARCHENA GÓMEZ, M.M. (1990): «Turismo y desarrollo: un planteamiento actual». Papers de Turisme, $\mathrm{n}^{\circ}$ 3, 59-84.

VERA REBOLLO, F., RODRÍGUEZ SÁNCHEZ, I.R. y CAPDEPÓN FRÍAS, M.C. (2011): Reestructuración y competitividad en destinos maduros de sol y playa: la renovación de la planta hotelera de Benidorm. En D. López (Ed.), Renovación de destinos turísticos consolidados (pp. 41-67). Valencia: Tirant Lo Blanch.

VIRGEN AGUILAR, C.R. (2009): «El ciclo de vida de un destino turístico: Puerto Vallarta, Jalisco, México». Cultura, n 3(01), 1-24.

WITT, S. F. y WITT, C.A. (1992): Modeling and Forecasting Demand in Tourism. Londres. Academic Press.

ZIELINSKI, S., y BOTERO SALTAREN, C. M. (2011): Percepción de la comunidad como indicador del ciclo de vida de un destino: Hacia el desarrollo de un sistema de alerta temprana para pequeños destinos. Estudios y perspectivas en turismo, $\mathrm{n}^{\circ} 20(6)$, disponible en: http://www.scielo.org.ar/scielo.php?script=sci_arttext\&pid=S1851$17322011000600008 \& \operatorname{lng}=\mathrm{es} \& \mathrm{nrm}=$ iso 
